\title{
Stepping Out of My Comfort Zone: A Valuable Teaching Experience for Medical Students
}

\author{
Robert DeVito and Peter Michael DeVito* \\ Northeast Ohio Medical University, Ohio, USA \\ *Corresponding author: Peter Michael DeVito, Northeast Ohio Medical University, Ohio, USA
}

\begin{tabular}{|c|c|}
\hline ARTICLE INFO & ABSTRACT \\
\hline Received: 幽 June 17, 2019 & Citation: Robert DeVito, Peter Michael DeVito. Stepping Out of My Comfort Zone: A Val- \\
\hline Published: 幽 June 25, 2019 & $\begin{array}{l}\text { uable Teaching Experience for Medical Students. Biomed J Sci \& Tech Res 19(1)-2019. } \\
\text { BJSTR. MS.ID.003256. }\end{array}$ \\
\hline
\end{tabular}

\section{Introduction}

Most mission statements for medical schools and hospitals proclaim their intent to "serve the underserved populations." This is a phrase that gets so much traffic its essential meaning can become jargon to medical students and residents. What really is an underserved population? Where are areas with low access to health care and resources? Who suffers these disparities? Certainly, there are populations like this in the United States. Geography plays a part; regions exist where there is not a hospital or medical specialist for 50 miles or more. But moreover, there are people who have not been examined by any type of healthcare provider in years. Homeless individuals, migrant populations, poor urban families, and elderly disenfranchised citizens are just some of the groups in distress in this and many other countries. Yet, these are the patients' medical students and residents very rarely interact with during core clerkships and residency training. Through hospital clinics, we deal with found needy individuals not lost individuals. My mission this summer was to participate in providing care to some members of these underserved populations.

When you really want to find out what something is, sometimes, you must leave your comfort zone and go outside your world to see it for yourself. I found NOAH NY, a non-profit health organization that provides the underserved people of Fort-Liberté, Haiti with access to healthcare. This organization has been running medical/surgical missions to Haiti annually since 2009. Since the 2010 earthquake in Port-au-Prince, Haiti, the need and scope of this mission has only increased. Infrastructure, access to healthcare and other basic necessities are still lacking, especially outside the capital. Through Dr. William Lois, chairman of the Department of Surgery at Bronx-
Lebanon Hospital in New York City and cochairman of surgery at American University of Antigua Medical School, this group brings family physicians, obstetricians, ophthalmologists and surgeons as well as nurses and pharmacists to the tiny hospital in Fort-Liberté for a week of medical service. This group partners with multiple medical schools including Northeast Ohio Medical University, Rootstown, Ohio, Howard University, Washington D.C., AUA and Touro College of Osteopathic Medicine in New York City, to bring more hands to help with the overwhelming need for medical care.

\section{The Mission}

We arrived in Cap Haitien, Haiti on June 23, 2018 and began the preliminary work of retrieving the medical supplies and medications the mission personnel from last year had left in storage. Much to our disappointment, a large amount of our supplies was destroyed by rats and other vermin and electrical malfunction of refrigerated storage had rendered the medications unusable. We gathered all the noncontaminated items and transported these supplies to FortLiberte, where we setup our exam rooms and operating rooms. On Monday, June 25 the real work began. I was assigned to a medical team that included a transplant surgeon, two general surgeons, two surgical residents, a podiatrist and seven medical students. By the end of the week our team performed 70 cases including, inguinal and ventral hernias, lower limb amputations for gangrene, breast lumpectomies, excisions of massive lipomas, adult circumcisions, and the incision and drainage of abscesses, one complicated by necrotizing fasciitis. We also participated in cesarean section deliveries. We operated each day as long as electricity was available, usually from $9 \mathrm{am}$ to $10 \mathrm{pm}$. We used the hospitals anesthesiologists, 
scrub nurses and surgical technicians. Post-operative care was also provided by the hospital [1].

One of the most compelling cases involved a 45-year-old woman with necrotizing fasciitis of the left buttock. Two weeks prior to being seen by our surgical team she had received an intramuscular birth control injection into her left buttock. This had developed into a horrible abscess and infection. Dr. Lois, a surgical resident and I performed a series of four surgeries on this patient. Initially, we removed subcutaneous fat, fascia, and muscle, deep enough to expose the femoral artery and sciatic nerve. We packed the wound with gauze and Betadine and gave intravenous Clindamycin. For the next three days, we returned to surgery removing more dead tissue, continuing dressing changes and IV medication. The patient repeatedly removed her own IV catheters and packing and dressings. Even when her IV access was changed to a central line, the patient found a way to remove it. The course of this woman's treatment was further complicated by her need for blood transfusions. In Haiti, the blood bank is run as an exchange program, meaning, in order for a patient to receive a blood transfusion, someone in their family must go to a local center and donate and equal number of units. By the time we were set to leave Haiti, this patient's infection had stopped spreading but she was in desperate need of blood transfusions. No one in her family has gone to donate blood, so no units were available to her [2].

The most common complications of our practice in Haiti was communication through language barriers. Haitian Creole, which is a combination of French, Portuguese, Spanish, English and Taino is the only language spoken by most Haitians. In US medical school, students learn to communicate with patients from day one. How to obtain a medical, social, family history and review of systems, perform a physical exam and outline a medical treatment plan are taught from the onset. But now this exchange of information is being filtered through interpreters as well as the biases and preconceived ideas of the participants. In these situations, you were always hoping important information like," We will be taking her back to surgery tonight" weren't lost in translation or worst of all mistranslated. One example was a five-year-old male with a symptomatic ventral hernia who was brought to us by his mother and their social worker. I worked up the patient, examined his hernia, and performed this history and physical with help of a translator. We already had a line of 30 to 40 people outside the surgical department waiting for the operative schedule announcement for the day. Unfortunately, we could not fit him in the schedule [3].
I explained to the patient's mother through the interpreter to return the next morning for the surgery. I watched the interpreter explain this to the patient and his mother. They acknowledged what he said and thanked me and the interpreter and left. I took down the patient's name discussed him with the faculty and added his name to the list of "To-Do" surgeries for the next day with the OR scheduler. The next morning the patient and his mother never showed up in the surgical department. Around lunchtime I went and looked for them around the hospital, hoping they were just waiting in a different area, but I never found them. Later in the day, I went out with the interpreter to again look for the boy and his mother. We searched multiple times, and no one had seen them. I wonder if we had spoken the same language, would they return for the surgery or explain they had no ride for the next day so other arrangements could be made. These cases showed me several issues in medicine that I will forever appreciate. Not every case has a happy ending. Not every case goes by the book. Not everyone who says yes really understands and follows instructions. Most importantly not every patient's world is filled with the resources to provide the standard of care we are taught to provide and expect to receive in the United States.

\section{Conclusion}

Do you want to find out what an underserved population really is after hearing so much about them in medical school lecture halls? I encourage everyone to go on a mission trip during your summer break. See the difference between a theoretical discussion and the real world. I look forward to going back next year for another opportunity to serve the people of Haiti. Helping the underserved is why so many of us go into medicine, and in Haiti I met some fantastic patients, families, and medical professionals. The people of Ft. Liberté are better off because of NOAH NY, and so am I.

\section{References}

1. Avashia YJ, Thaller SR (2011) Postearthquake Plastic Surgery Mission Trip to Port-Au-Prince, Haiti: a Medical Student's Perspective. Journal of Craniofacial Surgery 22(5): 1549-1551.

2. Gishen K, Thaller SR (2015) Surgical Mission Trips as an Educational Opportunity for Medical Students. Journal of Craniofacial Surgery 26(4): 1095-1096.

3. Hoang D, Nguyen KT (2011) Volunteering in Nha Trang, Vietnam: A Senior Medical Students' Perspectives of a Surgical Mission Trip. Yale J Biol Med 84(4): 461-470. 


\section{ISSN: 2574-1241}

DOI: 10.26717/BJSTR.2019.19.003256

Peter Michael DeVito. Biomed J Sci \& Tech Res

(c) (9) This work is licensed under Creative Commons Attribution 4.0 License

Submission Link: https://biomedres.us/submit-manuscript.php

$\begin{array}{ll}\begin{array}{l}\text { BIOMEDICAL } \\ \text { RESEARCHES }\end{array} & \text { Assets of Publishing with us } \\ \text { - Global archiving of articles } \\ \text { - Immediate, unrestricted online access }\end{array}$

